\title{
Modelling of the natural chlorine cycling in a coniferous stand: implications for chlorine-36 behaviour in a contaminated forest environment
}

Article

Accepted Version

Van Den Hoof, C. and Thiry, Y. (2012) Modelling of the natural chlorine cycling in a coniferous stand: implications for chlorine36 behaviour in a contaminated forest environment. Journal of Environmental Radioactivity, 107. pp. 56-67. ISSN 0265-931X doi: https://doi.org/10.1016/j.jenvrad.2011.12.014 Available at https://centaur.reading.ac.uk/26017/

It is advisable to refer to the publisher's version if you intend to cite from the work. See Guidance on citing.

Published version at: http://www.sciencedirect.com/science/article/pii/S0265931X11003092

To link to this article DOI: http://dx.doi.org/10.1016/j.jenvrad.2011.12.014

Publisher: Elsevier

All outputs in CentAUR are protected by Intellectual Property Rights law, including copyright law. Copyright and IPR is retained by the creators or other copyright holders. Terms and conditions for use of this material are defined in the End User Agreement. 


\section{CentAUR}

Central Archive at the University of Reading

Reading's research outputs online 


\title{
Modelling of the Natural Chlorine Cycling in a Coniferous Stand: Implications for Chlorine-36 Behaviour in a Contaminated Forest Environment
}

\author{
Catherine Van den Hoof ${ }^{\mathrm{a}, *}$, Yves Thiry ${ }^{\mathrm{b}}$ \\ ${ }^{a}$ SCK-CEN, Biosphere Impact Studies Unit, 200 Boeretang, $2400 \mathrm{Mol}$, Belgium \\ ${ }^{b}$ Andra, Research and Development Division, 1-7 rue Jean Monnet, 92298 \\ Châtenay-Malabry, France
}

\begin{abstract}
Considered as one of the most available radionuclide in soil-plant system, ${ }^{36} \mathrm{Cl}$ is of potential concern for long-term management of radioactive wastes, due to its high mobility and its long half-life. To evaluate the risk of dispersion and accumulation of ${ }^{36} \mathrm{Cl}$ in the biosphere as a consequence of a potential contamination, there is a need for an appropriate understanding of the chlorine cycling dynamics in the ecosystems. To date, a small number of studies have investigated the chlorine transfer in the ecosystem including the transformation of chloride to organic chlorine but, to our knowledge, none have modelled this cycle. In this study, a model involving inorganic as well as organic pools in soils has been developed and parameterised to describe the biogeochemical fate of chlorine in a pine forest. The model has been evaluated for stable chlorine by performing a range of sensitivity analyses and by comparing the simulated to the observed values. Finally a range of contamination scenarios, which differ in terms of external supply, exposure time and source, have been simulated to estimate the possible accumulation of ${ }^{36} \mathrm{Cl}$ within the different compartments of the coniferous stand. The sensitivity study supports the relevancy of the model and its compartments and has highlighted the chlorine transfers affecting the most the residence time of chlorine in the stand. Compared to observations, the model simulates realistic values for the chlorine content within the different forest compartments.
\end{abstract}

\footnotetext{
*Corresponding author.

Email addresses: catherine.vandenhoof@gmail.com.
} 
For both atmospheric and underground contamination scenarios most of the chlorine can be found in its organic form in the soil. However, in case of an underground source, about two times less chlorine accumulates in the system and proportionally more chlorine leaves the system through drainage than through volatilisation.

Keywords: Chlorine cycles, Coniferous forest, Modelling, Contamination assessment.

\section{Introduction}

Chlorine is a wide-spread element in natural environments. It is considered as one of the more mobile elements in soil and is also an essential micronutrient for higher plants (White and Broadley, 2001). Chlorine occurs in nature as two stable isotopes; chlorine-35 and chlorine- 37 with ${ }^{35} \mathrm{Cl}$ being the most prevalent. Of the seven radioactive chlorine isotopes, only one, chlorine-36, has a half-life longer than 1 hour. ${ }^{36} \mathrm{Cl}$ decays with a halflife of 300,000 years by emitting a beta particle and electron capture; most of the decays (98\%) are by beta-particle emission. ${ }^{36} \mathrm{Cl}$ is generated naturally by spallation in the atmosphere of argon-36 by cosmic ray protons, by interactions between cosmic radiation and $\mathrm{Cl}, \mathrm{Ca}$ and $\mathrm{K}$ in near-surface rocks and soils, and by neutron activation of ${ }^{35} \mathrm{Cl}$ in soil and rock (White and Broadley, 2001). ${ }^{36} \mathrm{Cl}$ is also produced anthropogenically during nuclear tests and nuclear industrial processes; i.e. ${ }^{36} \mathrm{Cl}$ is produced by neutron activation of ${ }^{35} \mathrm{Cl}$ present in materials used in nuclear reactors. As a consequence, waste fuel and certain construction materials originating from dismantling nuclear installation might contain ${ }^{36} \mathrm{Cl}$. Its mobility combined with its long half-life thus makes ${ }^{36} \mathrm{Cl}$ a radionuclide of potential concern for long-term management of radioactive wastes. High mobility in the soil column and a ready availability in soil solution (Ashworth and Shaw, 2006) allow ${ }^{36} \mathrm{Cl}$ to potentially contaminate the biosphere easily. Considered as one of the most available radionuclide for plants (Colle et al., 2002), ${ }^{36} \mathrm{Cl}$ was shown to have the same behaviour as stable $\mathrm{Cl}$ in soil and plants (Kashparov et al., 2007). Consequently, radio-chlorine is likely to be recycled in the biosphere and impact the food chain over a very long time.

Because chloride (Cl-), its widespread anionic form, has few affinities for the soil solid phase, chlorine is often considered as a conservative tracer of 
soil water movements with no implication in biological processes. While this view is valid in deep geological layers, it is questioned when considering surface soils due to the thousands of chlorinated organic compounds that are produced naturally in the biosphere (Winterton, 2000). The natural chlorination of soil organic matter (SOM) through biotic processes (Bastviken et al., 2009) seems largely responsible of the formation of organochlorine which was found to accumulate in large amount in certain organic soils e.g. coniferous forest (Redon et al., 2011). In many cases, the organic chlorine pool is often greater than the inorganic pool. In fact, the natural cycle of chlorine in soils is complex involving simultaneous formation and degradation of chlorinated organic compounds but attempts to rationalise sources and fluxes of organic and inorganic chlorines in soils are still scarce (Clarke et al., 2009). To evaluate the risk of dispersion and accumulation of ${ }^{36} \mathrm{Cl}$ in the biosphere due to a potential atmospheric or underground contamination, there is a need for an appropriate understanding and modelling of the chlorine cycling dynamics in a range of representative ecosystems.

The objective of this study is to develop a model describing the biogeochemical fate of chlorine in a coniferous forest based on measurements of stable chlorine performed in a pine forest around Mol (Belgium). During the measurements particular attention has been paid to the partitioning of the organic and inorganic chlorine into the different compartments of the ecosystem to better evaluate the contribution of the organic chlorine formation to the accumulation of chlorine within the ecosystem. Since ${ }^{36} \mathrm{Cl}$ has the same behaviour as stable chlorine in soils and plants, this model was then used as a questioning tool to estimate, under a range of contamination scenarios, the possible redistribution of ${ }^{36} \mathrm{Cl}$ between the different forest compartments.

\section{Materials}

\subsection{Study area and measurements}

The experimental Scots pine (Pinus sylvestris L.) stand is located at Mol in the Belgian Campine region. The local area has a rural and forested character with a high proportion of humid soils and wet zones. The topography is flat and the altitude is $15 \mathrm{~m}$. The 60 year old stand is part of a 189 ha forest dominated by Scots pine, with some patches of oak trees. In 2004, the stand density was 359 trees ha $^{-1}$. The mean height, circumference (at $1.3 \mathrm{~m}$ ) and 
stand basal area of the Scots pine were respectively $22 \mathrm{~m}, 0.91 \mathrm{~m}$ and 24.4 $\mathrm{m}^{2}$. In addition to grasses and mosses, the understorey vegetation mainly consists of Sorbus aucuparia, Prunus serotina, Rubus sp and Athyrium felix femina. The soil is a podzol and is classified as a distric Cambisol. The water table depth is very shallow. It fluctuates between $1.2 \mathrm{~m}$ to $0.5 \mathrm{~m}$ during spring and shows very strong intra-seasonal variations. A detailed description of the site can be found in Vincke and Thiry (2008).

During 2005 and 2006, a large number of soil and vegetation samples have been collected at this site. These samples were used to determine vegetation biomass and soil mass, as well as the levels of organic and inorganic chlorine in different compartments of the ecosystem. The chlorine content has been determined using the Neutron Activation Analysis technique. The procedures to differentiate the organic and inorganic chlorine content within the soil and vegetation samples have been adapted from Öberg et al. (2005). During the sampling campaign, the following items have been collected: water (precipitation and through-fall), tree (needles of one year and older, twigs, branches, wood, bark, roots), understorey (grasses, mosses, shrubs, ferns, fungi, berries) litter-fall (needles, bark, branches), and organic and mineral soil layers. The sampling procedures have been described in detail by Van Hees and Vandenhove (2009). In addition to a chlorine budget, the biological cycling dynamics in the pine stand was quantitatively described in terms of annual fluxes based on annual biomass production and respective average chlorine concentrations in the various tree compartments (Thiry, 2010). The calculations used to assess the element cycling were described in Goor and Thiry (2004).

\subsection{Speciation and distribution of chlorine in soil and vegetation}

In the pine stand, which is characterised by an atmospheric deposition of $12.6 \mathrm{~kg} \mathrm{ha}^{-1} \mathrm{yr}^{-1}$ of stable chlorine, a quantitative description of the chlorine budget and cycle resulted in the following conclusions (Thiry, 2010):

- The accumulation of chlorine in the soil at the pine stand is linked to the formation of organic chlorine. The transformation of inorganic to organic chlorine takes place once the decomposition of the humus has started in the $\mathrm{O}_{f}$ layer. Under our conditions, the rate of organic matter chlorination is estimated around $0.62 \mathrm{~kg} \mathrm{Cl} \mathrm{ha}{ }^{-1} \mathrm{yr}^{-1} .80 \%$ 
of the transformed inorganic chlorine originates from wet depositions. In the whole soil profile the concentration of organic chlorine is 3 to 4 times larger than the concentration of inorganic chlorine.

- Within the different tree compartments, the foliage has the largest chlorine concentration (590 $\mu \mathrm{g} \mathrm{Cl} \mathrm{g}{ }^{-1} \mathrm{~d}$.m.), accounting for roughly $35 \%$ of the total chlorine present in the tree. More than $90 \%$ of the chlorine in the leaves and the bark is in its inorganic form. This highlights the high chlorine mobility in the tree. The higher concentration of chlorine in the leaves compared to the soil $\left(27-279 \mu \mathrm{g} \mathrm{g}^{-1}\right)$ can be explained by the selective uptake of chlorine by the vegetation. On average, $20 \%$ of the chlorine present in the whole tree is in its organic form.

- The annual uptake of chlorine through root absorption is nine-fold larger than the chlorine demand by the tree, which is the total quantity of element mobilised by the current production of biomass (Goor and Thiry, 2004). This uptake takes place at a rate equivalent to the atmospheric deposition. The excess of chlorine is removed from the tree and returned to the soil through internal transfers at leaf level and subsequently through-fall. Under our conditions, litterfall plays a minor role in $\mathrm{Cl}$ return to the soil.

- The chlorine content within the tree biomass represents only $0.9 \%$ of the total chlorine content present in the whole pine stand. The chlorine content in the understorey and in the root system cannot be neglected since they represent respectively $1.2 \%$ and $0.5 \%$ of the total chlorine within the ecosystem at the stand. Most of the chlorine can be found in the forest floor $(5.7 \%)$ and in the mineral soil layer $(91.7 \%)$.

- Assuming that the system is in equilibrium, the residence time of chlorine was estimated based on a mass balance. In the tree the residence time is very short; i.e. 0.4 years. The residence time is longer in the forest floor and in the soil, respectively 3 and 47 years. The residence time of chlorine in the soil seems to be mainly regulated by the dynamics of the chlorination of organic matter and the biodegradation of organo-chlorinated compounds. The residence time of chlorine in the whole system is 48 years. 


\section{Methods}

\subsection{Model development}

In this study, the cycling of chlorine in the coniferous stand is represented by a seven-compartment model consisting of a mineral soil subdivided into an organic $\left(C_{1}\right)$ and inorganic $\left(C_{2}\right)$ chlorine pool, a forest floor component subdivided as well into organic $\left(C_{4}\right)$ and inorganic $\left(C_{3}\right)$ chlorine pool, a root component $\left(C_{5}\right)$, an above-ground tree component (wood and leaves, $C_{6}$ ) and a leaf surface component $\left(C_{7}\right)$. The drainage from the top $110 \mathrm{~cm}$ of the soil $\left(C_{8}\right)$ and the volatilisation $\left(C_{9}\right)$, both accounting for losses of chlorine out of the system, are identified as the eighth and ninth compartments. The chlorine input through atmospheric $\left(C_{10}\right)$ or underground supply $\left(C_{11}\right)$ are defined as the tenth and eleventh compartments. A conceptual scheme of the model is represented in Figure 1. This model structure is similar to that of models developed for forest ecosystems and radionuclides expected to interact with organic matter (Garten, 1978, 1987).

The above-mentioned compartments are interconnected by chlorine fluxes expressed in terms of fractions and transfer rates, $k_{i, j}$. Each flux rate represents the fractional transfer of chlorine from compartment i to compartment j. Nine flux rates were used to identify the chlorine cycling in the ecosystem. In addition to this, the atmospheric deposition on the external leaf surface $\left(k_{10,3}\right)$ and on the forest floor $\left(k_{10,7}\right)$, and the underground source $\left(k_{11,1}\right)$ were identified as the tenth, eleventh and twelfth fluxes. The change in the amount of chlorine over time in the different compartments is expressed as:

$$
\frac{d C_{i}}{d t}=\sum_{i}\left(\text { inputs to } C_{i}\right)-\sum_{i}\left(\text { outputs from } C_{i}\right)
$$

Based on Equation 1, the chlorine transfer between the different compartments can be determined by solving the following set of first-order linear differential equations:

$$
\begin{aligned}
\frac{d C_{1}}{d t} & =k_{11,1} C_{11} e^{-t / T_{s c}}+k_{5,1} C_{5}+k_{2,1} C_{2}+k_{3,1} C_{3}-\left(k_{1,5}+k_{1,8}\right) C_{1} \\
\frac{d C_{2}}{d t} & =k_{5,2} C_{5}+k_{4,2} C_{4}-\left(k_{2,8}+k_{2,1}\right) C_{2}
\end{aligned}
$$




$$
\begin{aligned}
\frac{d C_{3}}{d t} & =k_{5,3} C_{5}+k_{6,3} C_{6}+k_{7,3} C_{7}+k_{10,3} C_{10}-\left(k_{3,5}+k_{3,1}+k_{3,4}\right) C_{3} \\
\frac{d C_{4}}{d t} & =k_{6,4} C_{6}+k_{3,4} C_{3}+k_{5,4} C_{5}-\left(k_{4,2}+k_{4,9}\right) C_{4} \\
\frac{d C_{5}}{d t} & =k_{6,5} C_{6}+k_{3,5} C_{3}+k_{1,5} C_{1}-\left(k_{5,6}+k_{5,3}+k_{5,4}+k_{5,1}+k_{5,2}\right) C_{5} \\
\frac{d C_{6}}{d t} & =k_{7,6} C_{7}+k_{5,6} C_{5}-\left(k_{6,5}+k_{6,4}+k_{6,3}\right) C_{6} \\
\frac{d C_{7}}{d t} & =k_{10,7} C_{10} e^{-t / T_{a c}}-\left(k_{7,3}+k_{7,6}\right) C_{7} \\
\frac{d C_{8}}{d t} & =k_{1,8} C_{1}+k_{2,8} C_{2} \\
\frac{d C_{9}}{d t} & =k_{4,9} C_{4}
\end{aligned}
$$

where $T_{s c}$ and $T_{a c}$ are soil and atmosphere contamination/exposure time scales, respectively. For simulation with a constant level of contamination/exposure, $e^{-t / T_{s c}}$ and $e^{-t / T_{a c}}$ are set equal to 1 . The dimensioning of the model complexity was mainly set by the availability of data; i.e. measured or extracted from literature. The number of compartments and fluxes was assumed to be optimal for a realistic representation of the main chlorine pools in the forest stand.

In the model, the transfer rates can be defined either as deterministic or as following a (normal) probabilistic distribution with a given arithmetic mean and standard deviation. In the former case, the model is non-stochastic, while in the latter case the model is stochastic. With a stochastic model, ensemble simulations can be performed to investigate the model sensitivity to initial parameter values or temporal variability in parameter values. All fluxes between compartments could not be measured and were thus deduced based on reasonable hypothesis. The mean values attributed to these transfer rates are discussed in Section 3.2. Finally, the model has been developed based on a range of assumptions:

- The forest stand is in equilibrium.

- The behaviour of ${ }^{36} \mathrm{Cl}$ is similar to the behaviour of stable chlorine

- The transfer rates are time-independent. 
- The fluxes between compartments are controlled by the chlorine content in the donor compartment.

- As an initial condition, all the model compartments are assumed to be empty.

\subsection{Model parameterisation}

Fraction of atmospheric deposition onto leaf surface $\left(k_{10-7}\right)$ and forest floor - inorganic $\mathrm{Cl}$ pool $\left(k_{10-3}\right)$ The interception fraction of chlorine present in wet deposits is assumed to be equal to the interception fraction of the precipitation by the canopy. In the pine stand it is around 0.29 (Vincke and Thiry, 2008). This implies a value of 0.71 for the fraction not retained by leaf surface.

Fraction transferred from leaf surface to above-ground tree biomass $\left(k_{76}\right)$ This transfer corresponds to the translocation of an element deposited on the plant surface to other parts that were not directly exposed to the atmospheric deposition. A value of 0.15 was assigned to the parameter $k_{76}$. This relatively high value was selected in the light of recent field experiments on ${ }^{36} \mathrm{Cl}$ translocation in plants (Hurtevent et al., Submitted).

Fraction leached from leaf surface to forest floor - inorganic Cl pool $\left(k_{73}\right)$ The process of canopy weathering is the loss of material from leaf surface after wet deposition. Given the high solubility of chlorine, primarily as $\mathrm{Cl}^{-}$anion in atmospheric deposition (Öberg et al., 2005; Winterton, 2000), it is assumed that the residual deposits i.e. not absorbed within the foliage, are rapidly and efficiently removed through washing and leaching. A value of 0.845 was assigned to the parameter $k_{73}$, supposing that a small fraction of 0.005 could accumulate on the leaf surfaces.

Transfer from tree to forest floor - organic Cl pool $\left(k_{64}\right)$ The transfer of organic chlorine from tree to forest floor is assumed to be equal to the fraction of the organic chlorine content in the annual litterfall, $0.099 \mathrm{~kg}$ $\mathrm{ha}^{-1} \mathrm{yr}^{-1}$ (Thiry, 2010) and the total chlorine content in the pine tree, 5.5 $\mathrm{kg} \mathrm{ha}^{-1}$ (Thiry, 2010). This leads to an average transfer rate of $4.93 \times 10^{-5}$ $\mathrm{d}^{-1}$. 
Leaching from tree to forest floor - inorganic Cl pool $\left(k_{63}\right)$ In the pine stand, the mobilisation of chlorine via crown leaching is equal to $13.27 \mathrm{~kg} \mathrm{ha}^{-1} \mathrm{yr}^{-1}$ (Thiry, 2010). Given a total chlorine content of $5.5 \mathrm{~kg}$ $\mathrm{ha}^{-1}$ in the above-ground biomass, the leaching rate is estimated to be equal to $6.61 \times 10^{-3} \mathrm{~d}^{-1}$.

Transfers from the inorganic to the organic chlorine pool of the forest floor $\left(k_{34}\right)$ In the top layers of a forest soil, the transformation of inorganic to organic chlorine is mainly due to natural processes of organic matter chlorination (Bastviken et al., 2009). Therefore, the transfer rate $k_{34}$ was calculated based on the estimated chlorination rate and on the amount of inorganic chlorine measured in the $\mathrm{O}_{f}$ layer, which is around $2.6 \mathrm{~kg} \mathrm{ha}^{-1}$. As mentioned in Section 2.2, the chlorination rate at the pine stand was estimated to be $0.62 \mathrm{~kg} \mathrm{ha}^{-1} \mathrm{yr}^{-1}$ at the pine stand. This resulted in a value of $6.575 \times 10^{-4} \mathrm{~d}^{-1}$ for $k_{34}$.

Transfers from the organic to the inorganic chlorine pool of the soil $\left(k_{21}\right)$ There is a lack of information on the dynamics of $\mathrm{Cl}$ in organic matter of forest soils in general and on the biological degradation of organically bound chlorine in particular (Clarke et al., 2009). However, degrading organic matter seems to be a major source of inorganic chlorine in runoff (Lovett et al., 2005). A tentative balanced chlorine budget for a small forested catchment in Sweden (Öberg et al., 2005) suggested that a net mineralisation of organic chlorine takes place in soils, preferably in deeper mineral layers. In that study, the net mineralisation rate was estimated to be comparable to the rate of chlorination that is predominating in the top soil. Given a chlorination rate of $0.62 \mathrm{~kg} \mathrm{ha}^{-1} \mathrm{yr}^{-1}$, the degradation of organic chlorine to the inorganic form was estimated to be $4.22 \times 10^{-3} \mathrm{~d}^{-1}$. This value is the ratio between the mineralisation rate and the organic chlorine content of the soil, which is equal to $401 \mathrm{~kg} \mathrm{ha}^{-1}$ (Thiry, 2010).

Transfers of inorganic chlorine from the forest floor to the soil $\left(k_{31}\right) \quad$ The transfer rate $k_{31}$ was assumed to be equal to the leaching rate $\rho$, which has been estimated based on the formulations of Hillel (1998) and Holmberg et al. (1989):

$$
\rho=\frac{Q \times K(\theta)}{Z \times \theta}
$$


where $Q$ is the annual percolation, $K(\theta)$ the hydraulic conductivity, $Z$ the soil layer thickness and $\theta$ the volumetric soil moisture content in this soil layer. In the pine stand, the forest floor is $81 \mathrm{~mm}$ thick (Thiry, 2010). An average value of 0.15 was assigned to the volumetric soil water content $\theta$ (Vincke and Thiry, 2008). During the same year, the top soil layer percolation $Q$ was estimated at $453 \mathrm{~mm} \mathrm{yr}^{-1}$ (Vincke and Thiry, 2008), based on a precipitation rate $(\mathrm{P})$ of $815 \mathrm{~mm} \mathrm{yr}^{-1}$, a top canopy evaporation $\left(E_{c a n}\right)$ of $232 \mathrm{~mm} \mathrm{yr}^{-1}$ and an understorey transpiration $\left(T_{u}\right)$ of $130 \mathrm{~mm} \mathrm{yr}^{-1}(Q=$ $\left.P-E_{c a n}-T_{u}\right)$. The hydraulic conductivity $K(\theta)$ at the pine stand has been defined based on the conductivity at saturation $K\left(\theta_{\text {sat }}\right)$ and the Mualem (1976)'s model for predicting the relative hydraulic conductivity $K_{r}(\theta)$ from knowledge of the soil-water retention curve:

$$
\begin{gathered}
K(\theta)=K_{r}(\theta) \times K\left(\theta_{\text {sat }}\right) \\
K_{r}(\Theta)=\bar{\Theta}^{1 / 2}\left(1-\left(1-\bar{\Theta}^{1 / m}\right)^{n}\right)^{2}
\end{gathered}
$$

with $m$ and $n$ the dimensionless Mualem-van Genuchten parameters, and $\bar{\Theta}$ a dimensionless water content defined as:

$$
\bar{\Theta}=\frac{\left(\theta-\theta_{r}\right)}{\left(\theta_{s}-\theta_{r}\right)}
$$

with $s$ and $r$ indicating saturated and residual values of the soil water content $\theta$. The values of $K\left(\theta_{s a t}\right), m, n, \theta_{s}$ and $\theta_{r}$ were those computed by Wosten et al. (1999) for organic topsoils. Solving the above equations resulted in a leaching rate, and by consequence in a transfer rate value of $8.1 \times 10^{-3} \mathrm{~d}^{-1}$

Transfers of organic chlorine from the forest floor to the soil $\left(k_{42}\right)$ The leaching rate of organic chlorine from the forest floor was extrapolated from the organic matter balance estimated by Thiry (2010). The transfer factor $k_{42}$ in this study is set equal to the ratio of the litterfall rate, $2869 \mathrm{~kg} \mathrm{ha}^{-1} \mathrm{yr}^{-1}$, and the humus stock, $77259 \mathrm{~kg} \mathrm{ha}^{-1}$. This results in an annual average value of $1.01 \times 10^{-4} \mathrm{~d}^{-1}$. 
Export through leaching of inorganic chlorine from the soil $\left(k_{18}\right)$ Similarly to the transfer rate $k_{31}$, this transfer rate is estimated based on the water balance estimation in the pine stand. The thickness of the mineral soil layer is $1100 \mathrm{~mm}$ (Thiry, 2010) and its moisture content $\theta$ fluctuates around field capacity (Vincke and Thiry, 2008). The Mualem - van Genuchten parameters $\left(K\left(\theta_{s a t}\right), m, n, \theta_{s}\right.$ and $\left.\theta_{r}\right)$ values of this medium-textured soil have been taken from Wosten et al. (1999). The soil percolation $Q$ was estimated at $277 \mathrm{~mm} \mathrm{yr}^{-1}$ since this deeper soil layer is also influenced by the pine transpiration $\left(T_{p}\right)$, which during the sampling period was equal to176 $\mathrm{mm} \mathrm{yr}^{-1}$ (Vincke and Thiry, 2008). This resulted in a transfer rate $k_{18}$ of $2.2 \times 10^{-4}$ $\mathrm{d}^{-1}$

Export through leaching of organic chlorine from the soil $\left(k_{28}\right)$ In the absence of data on chlorine speciation in groundwater, the loss of organic chlorine was assumed to reflect the proportion of organic chlorine in drainage water as estimated by Öberg et al. (2005). Those authors indicated a form to total ratio of 0.01 for the organic form as opposed to 0.7 for the inorganic form of chlorine in the runoff water. The inorganic chlorine in the drainage water of the mineral soil at the stand is equal to the inorganic chloride content in the soil multiplied by $k_{18}$. Given this and the fact that the organic chlorine content in the soil is around $401 \mathrm{~kg} \mathrm{ha}^{-1}$, the leaching rate $k_{28}$ is estimated to be $1.21 \times 10^{-4} \mathrm{~d}^{-1}$.

Export through volatilisation of organic chlorine from the forest floor $\left(k_{49}\right)$ The transport of volatile organic chlorine from the forest floor to the atmosphere was estimated to be within the same range as the best estimates for the forest, i.e. $1 \mathrm{~kg} \mathrm{ha}^{-1} \mathrm{yr}^{-1}$, suggested by Öberg et al. (2005) based on other studies. Knowing that the forest floor within the pine stand contains $26.4 \mathrm{~kg}$ organic chlorine, the volatilisation rate has been estimated at $1.04 \times 10^{-4} \mathrm{~d}^{-1}$.

Transfers from soil and forest floor to roots $\left(k_{15}\right.$ and $\left.k_{35}\right)$ These transfers reflect the contribution of root absorption to the annual tree demand (Thiry, 2010). Plants acquire most of their chlorine from soil solution as chloride anions (Cl-) (White and Broadley, 2001). Accordingly, the inorganic pool of chlorine in the soil was considered to be the only source of chlorine for root absorption. Chlorine uptake by the aboveground biomass was computed as the sum of the chlorine immobilisation in the perennial 
compartments (wood, branches, bark) and the chlorine returns to the soil via litter-fall and through-fall. In the pine stand, this uptake has been estimated to be $13.7 \mathrm{~kg} \mathrm{ha}^{-1} \mathrm{yr}^{-1}$ (Thiry, 2010). In addition to this, chlorine uptake by trees includes the root consumption, i.e. $0.05 \mathrm{~kg} \mathrm{ha}^{-1} \mathrm{yr}^{-1}$ for coarse roots $(2-5 \mathrm{~mm})$ and $0.97 \mathrm{~kg} \mathrm{ha}^{-1} \mathrm{yr}^{-1}$ for fine roots $(<2 \mathrm{~mm})$. This results in a total tree chlorine uptake of $14.7 \mathrm{~kg} \mathrm{ha}^{-1} \mathrm{yr}^{-1}$. Based on active root distribution between the forest floor and the mineral soil, the proportion of chlorine uptake by the roots from both layers was assumed equal (Vincke and Thiry, 2008). Knowing that $8.1 \mathrm{~kg} \mathrm{ha}^{-1}$ inorganic chlorine were measured in the forest floor and $155 \mathrm{~kg} \mathrm{ha}^{-1}$ in the soil, the average annual uptake rates $k_{35}$ and $k_{15}$ were estimated to be respectively $2.49 \times 10^{-3} \mathrm{~d}^{-1}$ and $1.3 \times 10^{-4} \mathrm{~d}^{-1}$.

Transfers from roots to soil and forest floor $\left(k_{53}, k_{54}, k_{51}\right.$ and $k_{52}$ ) In the pine stand, the roots contain $4.7 \mathrm{~kg} \mathrm{ha}^{-1}$ of chlorine. The ratio between organic and inorganic chlorine in the small roots is around $0.29 / 0.71$ (Thiry, 2010). Small root turnover is usually considered as the main source of decomposed organic matter's return to the soil from the below-ground biomass (Vogt et al., 1996). In our model, the amount of chlorine allocated to the new small root $\left(<2 \mathrm{~mm}\right.$ ), $0.97 \mathrm{~kg} \mathrm{ha}^{-1} \mathrm{yr}^{-1}$ (see $k_{15}$ and $k_{35}$ ), is assumed to return to the soil through decay, while the amount allocated to the growing coarse roots is assumed to accumulate in the below-ground biomass. As mentioned earlier, the proportion of chlorine uptake by the roots from the forest floor is equal to the one from the mineral soil. Based on the inventory of organic and inorganic chlorine in the small roots, the average annual transfer rates of chlorine from the root system to the different soil and forest floor pools were $1.97 \times 10^{-4} \mathrm{~d}^{-1}$ for $k_{53}$ and $k_{51}$, and $8.22 \times 10^{-5} \mathrm{~d}^{-1}$ for $k_{54}$ and $k_{52}$.

Translocation from roots to above-ground tree biomass $\left(k_{56}\right)$ Chlorine is an essential micronutrient for plants. It was shown to be readily taken up by trees and to be highly mobile in pine trees (Thiry, 2010). The distribution pattern of chlorine in trees indicates a strong acropetal transfer with the highest chlorine concentrations measured in growing tissues; i.e. needles and twigs. In the pine stand, the transfer of chlorine from roots to the above-ground biomass was estimated to be $13.7 \mathrm{~kg} \mathrm{ha}^{-1} \mathrm{yr}^{-1}$ (Thiry, 2010). This flux corresponds to the translocation of chlorine taken up by roots that is not retained in tree roots. The transfer rate $k_{56}$ is defined as the ratio between this flux and the total chlorine content in the roots, which 
Table 1: Average annual values, expressed per day, assigned to the different transfer rates $k_{i j}$ 's

\begin{tabular}{ll}
\hline \hline Transfer rates & values $\left(\mathrm{d}^{-1}\right)$ \\
\hline$k_{10-7}$ & 0.29 \\
$k_{10-3}$ & 0.71 \\
$k_{11-1}$ & 1.0 \\
$k_{76}$ & 0.15 \\
$k_{73}$ & 0.845 \\
$k_{65}$ & $1.36 \times 10^{-3}$ \\
$k_{63}$ & $6.61 \times 10^{-3}$ \\
$k_{64}$ & $4.93 \times 10^{-5}$ \\
$k_{56}$ & $8 \times 10^{-3}$ \\
$k_{53}$ & $1.97 \times 10^{-4}$ \\
$k_{54}$ & $8.22 \times 10^{-5}$ \\
$k_{51}$ & $1.97 \times 10^{-4}$ \\
$k_{52}$ & $8.22 \times 10^{-5}$ \\
$k_{35}$ & $2.49 \times 10^{-3}$ \\
$k_{31}$ & $8.1 \times 10^{-3}$ \\
$k_{34}$ & $6.575 \times 10^{-4}$ \\
$k_{42}$ & $1.01 \times 10^{-4}$ \\
$k_{49}$ & $1.04 \times 10^{-4}$ \\
$k_{21}$ & $4.22 \times 10^{-6}$ \\
$k_{28}$ & $1.21 \times 10^{-6}$ \\
$k_{15}$ & $1.3 \times 10^{-4}$ \\
$k_{18}$ & $2.2 \times 10^{-4}$
\end{tabular}

is around $4.7 \mathrm{~kg} \mathrm{ha}^{-1}$ (Thiry, 2010). This results in a value of $8 \times 10^{-3} \mathrm{~d}^{-1}$ for $k_{56}$.

Translocation from above-ground tree biomass to roots $\left(k_{65}\right)$ The measurements performed at the site indicated a considerable decrease in $\mathrm{Cl}$ concentration in pine needles during senescence prior to leaf fall (Thiry, 2010). Chlorine appears to be highly mobile within the phloem. Accordingly, the recycling of $\mathrm{Cl}$, defined as the ratio of phloem/xylem nutrient fluxes, approximates 0.2 for many plants (White and Broadley, 2001). Consequently, given an acropetal flux of $13.7 \mathrm{~kg} \mathrm{ha}^{-1} \mathrm{yr}^{-1}$ (see $k_{56}$ ) and a total aboveground chlorine content of $5.5 \mathrm{~kg} \mathrm{ha}^{-1}$, a annual transfer rate of $1.36 \times 10^{-3}$ was considered to represent well the translocation of $\mathrm{Cl}$ from aboveground pine biomass to roots. 


\subsection{Model evaluation and applications}

Prior to studying the impact of a range of contamination scenarios on the accumulation and dispersion of ${ }^{36} \mathrm{Cl}$ within the different compartments of a pine stand system, the model was been evaluated for stable chlorine. First, the sensitivity of the model to the choice of the transfer rate values has been assessed. Next, the coherence between observed and simulated chlorine contents has been evaluated.

\subsubsection{Sensitivity to transfer rates}

A set of simulations was performed in order to evaluate the uncertainty related to the choice of the mean $k_{i j}$ value on the simulated chlorine content in the system. For each simulation within the ensemble of $l$ simulations, a random value drawn from a normal distribution with as mean value the values provided in Table 1 and a standard deviation of $20 \%$ from these mean values, was assigned to the transfer rates $k_{i j_{l}}$. A standard deviation of $20 \%$ was set arbitrarily. The impact of such a $20 \%$ uncertainty is evaluated by quantifying the variability of the simulated chlorine content given this standard deviation. The standard deviation $\sigma$ of the chlorine content in the system is used as a measure for the variability:

$$
\sigma=\sqrt{\frac{\sum_{l=1}^{n}\left(C_{l}-\bar{C}\right)^{2}}{n}}
$$

where $C_{l}$ is the individual simulated concentration of chlorine within the seven-compartments system for each specific $k_{i j_{l}}$ value, and $\bar{C}$ is the mean of the $C_{l}$ values.

In order to evaluate the role of each transfer rate on the dispersion and accumulation of the chlorine within the seven-compartment system, the correlation between the selected transfer rate $k_{i j}$ and the chlorine content in the compartments has been computed using the determination coefficient, $r$ :

$$
r_{i j}=\frac{\sum_{l=1}^{n}\left(k_{i j_{l}}-\bar{k}_{i j}\right)\left(C_{l}-\bar{C}\right)}{\left(\sum_{l=1}^{n}\left(k_{i j_{l}}-\bar{k}_{i j}\right)^{2} \sum_{l=1}^{n}\left(C_{l}-\bar{C}\right)^{2}\right)^{1 / 2}}
$$


where $k_{i j_{l}}$ are the individual values assigned to the transfer rate $k_{i j}$, and $k_{i j}$ the mean of $k_{i j_{l}}$. This correlation coefficient is a direct measure of how well the transfer factor $k_{i j}$ and the concentration within the compartments vary jointly. The values assigned to $k_{i j_{l}}$ were a set of values around the mean transfer rate provided in Section 3.2, with a range extending from $-50 \%$ to $+50 \%$. The sensitivity and the correlation studies were performed for both underground and atmospheric chlorine supplies of $10 \mathrm{~kg} \mathrm{ha}^{-1} \mathrm{yr}^{-1}$ of stable chlorine after a simulation of 2000 years.

\subsubsection{Simulations versus observations}

As mentioned in Section 2.2, an atmospheric deposition of $12.6 \mathrm{~kg} \mathrm{ha}^{-1}$ $\mathrm{yr}^{-1}$ of stable chlorine has been observed at the pine stand (Thiry, 2010). Given this rate, the simulated chlorine content is compared to the observed content in the different compartments of the system. The significance of their differences are evaluated and discussed in Section 4.2.

\subsubsection{Contamination scenarios}

Once the model had been evaluated, a range of contamination scenarios were simulated to estimate the possible redistribution of ${ }^{36} \mathrm{Cl}$ between the different forest compartments. These scenarios differ from each other by their source, external supply and exposure time. An external chronic atmospheric supply of $10 \mathrm{~Bq} \mathrm{ha}{ }^{-1} \mathrm{yr}^{-1}$ has been taken arbitrarily as the reference scenario. Next, a chronic underground source of $10 \mathrm{~Bq} \mathrm{ha}^{-1} \mathrm{yr}^{-1}$ was simulated. The chlorine content and partitioning within the different compartments of the system for both scenarios were compared to each other to evaluate the impact of the contamination source. Finally, the exposure time to an atmospheric contamination of $10 \mathrm{~Bq} \mathrm{ha}{ }^{-1} \mathrm{yr}^{-1}$ has been limited to 2000 years, 100 years and 1 year. The model outputs for these different scenarios have been compared as well, in particular the partitioning and residence time of the chlorine in the different compartment. 


\section{Results and discussion}

\subsection{Sensitivity to transfer rates}

4.1.1. Impact of transfer rates uncertainty on chlorine accumulation in system

The impact of the uncertainty related to the values assigned to the transfer rates has been evaluated by quantifying the sensitivity of the simulated chlorine content in the system to a $20 \%$ variation in transfer rate value. The resulting normalised standard deviation from the simulated mean chlorine content (in \%) in each compartment, as well as in the total system, are provided in Table 2 for a chronic atmospheric deposition (top) and underground source (bottom) of $10 \mathrm{~kg} \mathrm{ha}^{-1} \mathrm{yr}^{-1}$ of stable chlorine. The sum of the standard deviations per compartment and per transfer rate are given as well.

Table 2 shows that an uncertainty of $20 \%$ on all transfer rates results in a variability of the total chlorine content, and by consequence on the residence time of chlorine in the system, of around $25 \%$ for both underground and atmospheric sources. In fact, the variability increases very rapidly during the first 15 years of the simulations, with an average increase of $1 \% \mathrm{yr}^{-1}$, decreasing later to a roughly $0.0025 \% \mathrm{yr}^{-1}$ (data not shown) annual increase .

The sensitivity of the model however depends on the transfer rate and the chlorine source. In the case of atmospheric deposition, the total chlorine content and the residence time in the system is very sensitive to a variation in the transfer of inorganic $\mathrm{Cl}$ from the forest floor to the soil $\left(k_{31}\right)$, and to a lesser extent to a variation in the mineralisation of organic chlorine in the soil $\left(k_{21}\right)$ and a variation in the drainage of inorganic chlorine out of the soil $\left(k_{18}\right)$, resulting respectively in a variability of $13 \%, 11.1 \%, 9.9 \%$ of the total content in the system given a 20\% uncertainty for these transfers. For an underground supply, the model is very sensitive to the value of $k_{18}$, and to less extent to a variation in $k_{21}$ and $k_{15}$ (transfer from soil to roots), resulting respectively in a variability of $19 \%, 10.2 \%, 10 \%$ of the total content in the system. The value assigned to the transfer from the inorganic to the organic chlorine pool of the forest floor $\left(k_{34}\right)$ affects moderately the chlorine content in the system.

Focussing now on the sensitivity of the individual compartments of the system, Table 2 shows that under both scenarios, $k_{31}, k_{18}$ and $k_{15}$ have a 
Table 2: The normalised standard deviation from the mean chlorine content (in \%) for each compartment given a $20 \%$ uncertainty on the transfer rates value for a chronic atmospheric deposition (top) and underground source (bottom) of $10 \mathrm{~kg}$ $h a^{-1} \mathrm{yr}^{-1}$ of stable chlorine, after a simulation of 2000 years.

\begin{tabular}{l|lllllll|l|l}
$k_{i} \backslash C_{i}$ & $C_{1}$ & $C_{2}$ & $C_{3}$ & $C_{4}$ & $C_{5}$ & $C_{6}$ & $C_{7}$ & $\sum$ & $C_{\text {tot }}$ \\
\hline$k_{10-7}$ & $<0.1$ & 0.1 & $<0.1$ & $<0.1$ & 0.1 & 0.9 & 19.0 & 20.1 & 0.1 \\
$k_{76}$ & $<0.1$ & 0.1 & $<0.1$ & $<0.1$ & 0.1 & 0.8 & $<0.1$ & 1.0 & 0.1 \\
$k_{65}$ & $<0.1$ & 0.7 & 0.2 & $<0.1$ & 3.5 & 0.4 & $<0.1$ & 4.8 & 0.6 \\
$k_{63}$ & 0.1 & 1.3 & 0.2 & 0.9 & 2.8 & 17.7 & $<0.1$ & 23.0 & 1.1 \\
$k_{64}$ & 0.1 & 0.7 & 0.1 & 0.9 & 0.1 & 0.2 & $<0.1$ & 2.1 & 0.5 \\
$k_{56}$ & 0.1 & 4.3 & 0.9 & $<0.1$ & 19.1 & 2.1 & $<0.1$ & 26.5 & 3.2 \\
$k_{53}$ & $<0.1$ & 0.1 & $<0.1$ & $<0.1$ & 0.6 & 0.5 & $<0.1$ & 1.2 & 0.1 \\
$k_{54}$ & 0.1 & 0.9 & 0.1 & 1.1 & 0.3 & 0.3 & $<0.1$ & 2.8 & 0.7 \\
$k_{51}$ & $<0.1$ & 0.4 & 0.3 & 0.3 & 0.6 & 0.6 & $<0.1$ & 2.2 & 0.3 \\
$k_{52}$ & $<0.1$ & 2.6 & 0.1 & 0.2 & 0.3 & 0.3 & $<0.1$ & 3.5 & 1.8 \\
$k_{35}$ & 0.1 & 1.5 & 0.3 & 0.3 & 6.0 & 5.7 & $<0.1$ & 13.9 & 1.2 \\
$k_{31}$ & 1.8 & 17.7 & 21.5 & 20.2 & 8.5 & 8.1 & $<0.1$ & 77.8 & 13.5 \\
$k_{34}$ & 1.1 & 10.5 & 1.6 & 13.8 & 1.4 & 1.3 & $<0.1$ & 29.7 & 7.8 \\
$k_{42}$ & 0.6 & 9.7 & 0.2 & 11.2 & 0.4 & 0.4 & $<0.1$ & 22.5 & 6.8 \\
$k_{49}$ & 0.5 & 9.0 & 0.2 & 11.3 & 0.4 & 0.4 & $<0.1$ & 21.8 & 7.0 \\
$k_{21}$ & 0.4 & 15.4 & 0.1 & 0.1 & 0.3 & 0.3 & $<0.1$ & 16.6 & 11.1 \\
$k_{28}$ & 0.3 & 4.8 & 0.1 & 0.1 & 0.2 & 0.2 & $<0.1$ & 5.7 & 3.6 \\
$k_{15}$ & 0.7 & 9.2 & 7.0 & 7.7 & 14.6 & 14.1 & $<0.1$ & 53.3 & 7.0 \\
$k_{18}$ & 17.6 & 7.8 & 5.9 & 6.6 & 12.4 & 11.9 & $<0.1$ & 62.2 & 9.9 \\
\hline$\sum$ & 23.5 & 96.8 & 38.8 & 74.7 & 71.7 & 66.2 & 19.0 & & 76.4 \\
\hline$k_{\text {all }}$ & 19.8 & 30.2 & 24.9 & 31.9 & 32.1 & 24.1 & 13.8 & 176.8 & 23.1
\end{tabular}

\begin{tabular}{l|lllllll|l|l}
$k_{i} \backslash C_{i}$ & $C_{1}$ & $C_{2}$ & $C_{3}$ & $C_{4}$ & $C_{5}$ & $C_{6}$ & $C_{7}$ & $\sum$ & $C_{\text {tot }}$ \\
\hline$k_{10-7}$ & $<0.1$ & $<0.1$ & $<0.1$ & $<0.1$ & $<0.1$ & $<0.1$ & NA & $<0.1$ & $<0.1$ \\
$k_{76}$ & $<0.1$ & $<0.1$ & $<0.1$ & $<0.1$ & $<0.1$ & $<0.1$ & NA & $<0.1$ & $<0.1$ \\
$k_{65}$ & $<0.1$ & 0.9 & 0.2 & $<0.1$ & 2.6 & 0.3 & NA & 4.0 & 0.5 \\
$k_{63}$ & 0.1 & 2.3 & 0.5 & 1.9 & 3.0 & 18.7 & NA & 26.5 & 1.5 \\
$k_{64}$ & 0.1 & 1.3 & 0.3 & 2.1 & 0.1 & 0.3 & NA & 4.2 & 0.8 \\
$k_{56}$ & 0.1 & 7.4 & 2.0 & $<0.1$ & 20.4 & 2.4 & NA & 32.3 & 4.4 \\
$k_{53}$ & $<0.1$ & 0.2 & $<0.1$ & 0.1 & 0.6 & 0.6 & NA & 1.5 & 0.1 \\
$k_{54}$ & 0.1 & 2.0 & 0.4 & 2.8 & 0.4 & 0.4 & NA & 6.1 & 1.1 \\
$k_{51}$ & $<0.1$ & 0.7 & 0.7 & 0.7 & 0.7 & 0.7 & NA & 3.5 & 0.4 \\
$k_{52}$ & $<0.1$ & 4.0 & 0.3 & 0.3 & 0.3 & 0.3 & NA & 5.2 & 2.2 \\
$k_{35}$ & $<0.1$ & 1.6 & 0.4 & 0.4 & 3.9 & 3.9 & NA & 10.2 & 1.0 \\
$k_{31}$ & 0.5 & 11.8 & 18.8 & 16.0 & 3.5 & 3.5 & NA & 54.1 & 7.0 \\
$k_{34}$ & 0.5 & 10.7 & 2.1 & 16.9 & 0.8 & 0.8 & NA & 31.8 & 6.1 \\
$k_{42}$ & 0.2 & 6.3 & 0.2 & 9.1 & 0.2 & 0.2 & NA & 16.2 & 3.5 \\
$k_{49}$ & 0.2 & 6.1 & 0.2 & 9.2 & 0.2 & 0.2 & NA & 16.1 & 3.8 \\
$k_{21}$ & 0.2 & 17.6 & 0.2 & 0.2 & 0.2 & 0.2 & NA & 18.6 & 10.2 \\
$k_{28}$ & 0.1 & 3.3 & 0.1 & 0.1 & 0.1 & 0.1 & NA & 3.8 & 1.9 \\
$k_{15}$ & 0.6 & 16.5 & 16.6 & 16.6 & 16.6 & 16.6 & NA & 83.5 & 10.0 \\
$k_{18}$ & 19.0 & 19.0 & 19.0 & 19.0 & 19.0 & 19.0 & NA & 114 & 19.0 \\
\hline$\sum$ & 21.7 & 111.7 & 62 & 95.4 & 72.6 & 68.2 & NA & & 73.5 \\
\hline$k_{a l l}$ & 20.4 & 37.7 & 35.9 & 36.4 & 28.3 & 31.4 & NA & 190.1 & 26.7
\end{tabular}


large impact on the individual compartments. At the individual level $k_{21}$ is the only one significantly affecting the organic chlorine pool of the soil $\left(C_{2}\right)$. $k_{31}$ has a large impact on this pool as well and on the inorganic $\left(C_{3}\right)$ and organic chlorine pool of the forest floor $\left(C_{4}\right)$. A $20 \%$ uncertainty on $k_{31}$ under the atmospheric deposition scenario results in a variability of $21.5 \%$ for $C_{3}$, $20.2 \%$ for $C_{4}$ and $17.7 \%$ for $C_{2}$. Under the underground supply scenario, it results in a variability of $18.8 \%, 16.0 \%$ and $11.8 \%$, respectively. $k_{15}$ has a large impact on the chlorine content of the roots $\left(C_{5}\right)$ and the tree $\left(C_{6}\right)$. A $20 \%$ uncertainty on $k_{15}$ in both scenarios results in a variability of around $15 \%$ of the chlorine content in $C_{5}$ and $C_{6}$. Under the underground supply scenario, this parameter affects largely the content of $C_{2}, C_{3}$ and $C_{4}$ as well. A variation of the $k_{18}$ value has a large impact on the chlorine content in the drainage water (not shown in Table 2) and in the inorganic chlorine pool of the soil $\left(C_{1}\right)$. A $20 \%$ uncertainty on $k_{18}$, under both scenarios, results in a variability of slightly less than $20 \%$ on the chlorine content in $C_{1}$. In case of an underground supply, this parameter has also the same large impact on $C_{2}, C_{3}, C_{4}, C_{5}$ and $C_{6}$. Finally a $20 \%$ uncertainty on the chlorination rate in the forest floor $\left(k_{34}\right)$ has a significant effect $(>10 \%)$ on the chlorine content in $C_{2}$ and $C_{4}$.

On the other hand, some parameters have almost no impact on the chlorine content in the system and its different compartments. Under the underground supply scenario, the partitioning of the atmospheric deposition between leaf surface $\left(k_{10-7}\right)$ and forest floor $k_{10-3}$ and the partitioning of the chlorine on the leaf surface between the tree $\left(k_{76}\right)$ and the forest floor $\left(k_{73}\right)$ have no impact on the chlorine content. However, in case of an atmospheric deposition scenario, $k_{10-7}$ and $k_{10-3}$ have a significant impact, $19 \%$, on the amount of chlorine on the leaf surface $\left(C_{7}\right)$. Under this scenario, $k_{76}$ and $k_{73}$ have no significant impact on the chlorine content. The transfer from the roots to the inorganic chlorine pool of the forest floor $\left(k_{53}\right)$ has no significant impact under both scenarios. Other parameters such as the transfers from the tree to the roots $\left(k_{65}\right)$ and to the organic chlorine pool of the forest floor $\left(k_{64}\right)$, and from the roots to the organic chlorine pool of the forest floor $\left(k_{54}\right)$ and to the inorganic chlorine pool of the soil $\left(k_{51}\right)$ have a fairly small impact on the chlorine content. The same is valid for the drainage rate from the organic chlorine pool of the soil $\left(k_{28}\right)$ in case of the underground supply scenario. 
Table 2 also shows that the chlorine content of some compartments is almost uninfluenced by the value assigned to the transfer rates. This is the case of the leaf surface compartment $C_{7}$, except under the atmospheric deposition scenario where it is significantly affected by a variation of the $k_{10-7}$ value. The impact of transfer rate uncertainty on the chlorine content in the inorganic chlorine pool of the soil $\left(C_{1}\right)$ is also fairly small. This compartment is only significantly affected by $k_{18}$ i.e. the leaching of inorganic chlorine from the soil. The content of organic chlorine in the soil $\left(C_{2}\right)$, on the other hand, is strongly affected by the values assigned to transfer rates. This compartment is the most affected by each transfer rate individually. The chlorine content in the organic pool of the forest floor $\left(C_{4}\right)$, in the roots $\left(C_{5}\right)$ and in the tree $\left(C_{6}\right)$ compartments, which are both strongly linked, are in general quite sensitive to the different transfer rates as well.

From Table 2 it can be seen that the sum of the impact of each individual transfer rate uncertainty on the chlorine content in the system and its compartments is much larger than the impact of all transfer rate uncertainties in one simulation. This means that the system is acting as a buffer to smooth out the overall effect of variation in the transfer rates. The variation in the whole system is smaller than the variation in the individual components. By consequence, in our model, it is expected that environmental changes would have less impact at the system scale than at the individual component scale. The processes within the system interact with each other, in agreement with the high dynamics characterising the chlorine cycling.

\subsubsection{Correlation between transfer rates and chlorine content in the system}

The role of each transfer rate on the chlorine content within the system and its different compartments has been evaluated by quantifying the correlation between the simulated chlorine content and the transfer rate values.

The values of the Pearson correlation between the transfer rates and the chlorine content in the different compartments are provided in Table 3 for a chronic atmospheric deposition of $10 \mathrm{~kg} \mathrm{ha}^{-1} \mathrm{yr}^{-1}$ of stable chlorine. The values are only mentioned for correlations with significances larger or equal to $95 \%$. The correlation coefficients were similar for a chronic underground source (data not shown), except the correlation between the transfer rates and the leaf surface compartment $C_{7}$. In case of underground supply, there is 
Table 3: Pearson correlation $(p<0.05)$ between the chlorine content in the different compartments and the transfer factors for a chronic atmospheric deposition of 10 $\mathrm{kg} \mathrm{ha}^{-1} \mathrm{yr}^{-1}$ of stable chlorine, after a simulation of 2000 years.

\begin{tabular}{l|llllllll}
$k_{i} \backslash C_{i}$ & $C_{1}$ & $C_{2}$ & $C_{3}$ & $C_{4}$ & $C_{5}$ & $C_{6}$ & $C_{7}$ & $C_{\text {tot }}$ \\
\hline$k_{10-7}$ & -1 & 1 & -1 & 1 & 1 & 1 & 1 & 1 \\
$k_{76}$ & -0.99 & 0.99 & -1 & 1 & 1 & 1 & & 0.99 \\
$k_{65}$ & -1 & 1 & -1 & 0.99 & 1 & -1 & & 1 \\
$k_{63}$ & 0.95 & -0.95 & 0.95 & -0.95 & -0.95 & -0.95 & & -0.95 \\
$k_{64}$ & -1 & 1 & -1 & 1 & -1 & -1 & 0.99 & 1 \\
$k_{56}$ & 0.97 & -0.97 & 0.97 & -0.97 & -0.97 & 0.97 & & -0.97 \\
$k_{53}$ & 1 & -1 & 1 & -1 & -1 & -1 & 0.99 & -1 \\
$k_{54}$ & -1 & 1 & -1 & 1 & -1 & -1 & 0.99 & 1 \\
$k_{51}$ & 0.99 & -0.99 & -0.99 & -0.99 & -0.99 & -0.99 & 0.54 & -0.99 \\
$k_{52}$ & -1 & 1 & -1 & -1 & -1 & -1 & -0.99 & 1 \\
$k_{35}$ & -1 & 1 & -1 & 1 & 1 & 1 & & 1 \\
$k_{31}$ & 0.96 & -0.96 & -0.96 & -0.96 & -0.96 & -0.96 & & -0.96 \\
$k_{34}$ & -0.99 & 0.99 & -0.99 & 0.99 & -0.99 & -0.99 & & 0.99 \\
$k_{42}$ & 0.99 & 0.99 & 0.99 & -0.99 & 0.99 & 0.99 & & 0.99 \\
$k_{49}$ & -0.99 & -0.99 & -0.99 & -0.99 & -0.99 & -0.99 & & -0.99 \\
$k_{21}$ & 0.97 & -0.98 & 0.97 & 0.97 & 0.97 & 0.97 & & -0.98 \\
$k_{28}$ & -0.99 & -0.99 & -0.99 & -0.99 & -0.99 & -0.99 & & -0.99 \\
$k_{15}$ & -1 & 1 & 1 & 1 & 1 & 1 & & 1 \\
$k_{18}$ & -0.96 & -0.96 & -0.96 & -0.96 & -0.96 & -0.96 & & -0.96
\end{tabular}

no chlorine deposition on the leaf surface, and consequently there is no correlation possible with transfer rates. In the case of atmospheric deposition, the chlorine content within this compartment is only significantly correlated with the partitioning of the deposition between leaf and forest floor compartments $\left(k_{10-7}\right.$ and $k_{10-3}$, and with the transfers from roots to forest floor and soil $\left(k_{64}, k_{53}, k_{54}, k_{51}\right.$ and $\left.k_{52}\right)$.

Table 3 shows that, overall, the chlorine contents and the transfer rates are strongly correlated and that the correlations between both are very linear. There are however strong differences between transfer rates and compartments regarding the sign of the correlations. The parameters that show a positive correlation with the chlorine content in $C_{2}$; i.e. $k_{10-7}, k_{76}, k_{65}, k_{64}$, $k_{54}, k_{52}, k_{35}, k_{34}, k_{42}$ and $k_{15}$, show a positive correlation with the total chlorine content in the system as well, and inversely for the other parameters. This means that, based on the sensitivity analysis performed in previous section, an increase of the uptake rate of inorganic chlorine by the roots $\left(k_{15}\right)$ 
or the chlorination rate in the forest floor compartment $\left(k_{34}\right)$ would lead to a significant increase of the total chlorine content and its residence time in the system. This can be explained by the fact that an increase of the chlorination process $\left(k_{34}\right)$ in the forest floor increases the amount of chlorine immobilised in the organic pools of the soil profile, and that a larger uptake of inorganic chlorine by the roots $\left(k_{15}\right)$, in particular in case of underground supply, results in more substantial recycling and may contribute to an enhanced stabilisation of chlorine in the system.

On the other hand, an increase in the leaching rate from forest floor and soil $\left(k_{31}\right.$ and $\left.k_{18}\right)$ and the degradation of organic compounds in the mineral soil $\left(k_{21}\right)$ would lead to a significant decrease of the total chlorine content and its residence time in the system. An increase of the values assigned to $k_{49}, k_{18}$ and $k_{28}$, which are the fluxes through which chlorine leaves the system, logically results in a decrease of the chlorine content in each compartment and by consequence of the total chlorine content in the system. Next, a higher leaching of soluble inorganic chlorine $\left(k_{31}\right)$ in the forest floor $\left(C_{3}\right)$ reduces on one hand the amount of inorganic chlorine available for chlorination in $C_{3}$, and therefore reduces the amount of chlorine in the organic pools $\left(C_{2}\right.$ and $\left.C_{4}\right)$. It also increases temporarily the inorganic chlorine content in the mineral soil $\left(C_{1}\right)$ and consequently enhances the leaching of chlorine out of the system. Finally, a higher degradation rate in the mineral soil $\left(k_{21}\right)$ reduces the amount of organic chlorine in the soil $\left(C_{2}\right)$ and temporarily increases the amount of soluble inorganic chlorine in the soil, which is very quickly leached out of the system.

\subsection{Simulations versus observations}

The result of the simulations performed with the parameterisation provided in Table 1 and forced with a continuous atmospheric deposition of 12.6 $\mathrm{kg} \mathrm{ha} \mathrm{yr}^{-1}$ of stable chlorine has been compared to the observed chlorine content in the different compartments of the system. The times series of the simulated chlorine content and percentage within the compartments of the system are shown in Figure 2. The observed values are represented by black dots. From Fig.2 it can be seen that the equilibrium state for the whole system is reached after around 2000 years. In fact, the compartments already reach their equilibrium within 100 years except for the organic pool of chlorine in the soil, which requires around 2000 years. This is quite similar 
to the timeframe required for the soil carbon pool to reach equilibrium after disturbance (Liberloo et al., 2010; Wutzler and Reichstein, 2006). The major causes for this postponed steady-state are the chlorination of organic matter and the further evolution of organic chlorine in the soil.

In Table 4, the chlorine content in the different compartments after a simulation of 2000 years is compared to the observed values. The simulated content is in reasonable agreement with these observed values; they differ by less than 20\% except the inorganic chlorine pool of the forest floor, which differ by $28 \%$. No values were measured for the external leaf surface compartment. The simulated chlorine contents tend to underestimate the observed ones, except for the organic chlorine content in the soil, which is overestimated by $16 \%$. Based on the correlation study in Section 4.1.2, an increase of the value assigned to $k_{21}$ (mineralisation of organic chlorine in soil) or a decrease of the value assigned to $k_{52}$ (return of organic chlorine to the soil through root decay) would lead to a better match between observations and simulations. As mentioned in Sections 3.2 and 4.1.1, given the large uncertainty related to the value assigned to transfers from organic to inorganic chlorine pool of the soil $\left(k_{21}\right)$ and the fact that the model is very sensitive to this parameter, further studies on the process of degradation of organic chlorine to its inorganic form would be needed to explain this bias between observations and simulations.

Table 4: Observed and simulated chlorine content in the different compartments for a chronic atmospheric deposition of $12.6 \mathrm{~kg} \mathrm{Cl} \mathrm{ha}^{-1} \mathrm{yr}^{-1}$. The results are given in $\mathrm{kg} / \mathrm{ha}$ for a system close to equilibrium.

\begin{tabular}{l|llllllll} 
& $C_{1}$ & $C_{2}$ & $C_{3}$ & $C_{4}$ & $C_{5}$ & $C_{6}$ & $C_{7}$ & $C_{t o t}$ \\
\hline Observations & 155 & 401 & 8.1 & 26.4 & 4.7 & 5.5 & NA & NA \\
Simulations & 144 & 466 & 5.8 & 21.7 & 4.7 & 4.8 & 0.01 & 647
\end{tabular}

\subsection{Contamination scenarios}

\subsubsection{Atmospheric versus underground}

In Figure 3 (top), the content and the percentage of chlorine in the different compartments of the system are represented for an atmospheric con- 
tamination of ${ }^{36} \mathrm{Cl}$ at a rate of $10 \mathrm{~Bq} \mathrm{ha}^{-1} \mathrm{yr}^{-1}$. During the first year of the model simulation, most of the chlorine can be found in the inorganic pool of the forest floor. During the second year of the simulations, the content becomes the largest in the inorganic pool of the mineral soil. ${ }^{36} \mathrm{Cl}$ however continues to accumulate in the organic pool of the soil and, after around 200 years of simulations, it becomes the largest pool. The system however will require around 2000 years to reach its equilibrium state.

The leaf surface is the first pool to reach equilibrium ( $<1$ year), followed consecutively by the roots, the tree and the inorganic pool of the forest floor compartments (50 years), the organic forest floor (75 years) and the inorganic soil (100 years) compartments. The organic chlorine pool reaches its equilibrium after around 2000 years and contains $370 \mathrm{~Bq} \mathrm{ha}^{-1}$, which corresponds to around $72 \%$ of the total chlorine content in the system. At equilibrium, the inorganic pool of the soil is the second largest pool and represents $22 \%$ of the total chlorine content. The leaf surface, the inorganic pool of the forest floor, the roots and the tree represent together less than $2.5 \%$ of the total chlorine content. The organic pool of the forest floor represents $3.3 \%$.

After 2000 years of model simulation, a cumulative amount of $20 \times 10^{3}$ $\mathrm{Bq} \mathrm{ha}{ }^{-1}$ of ${ }^{35} \mathrm{Cl}$ have entered the system through atmospheric contamination, from which $513,7 \mathrm{~Bq} \mathrm{ha}^{-1}$ or $2.6 \%$ is still in the system at equilibrium. Over this period, around $19500 \mathrm{~Bq} \mathrm{ha}{ }^{-1}$ of ${ }^{36} \mathrm{Cl}$ has left the system, 93.3\% through drainage and only $6.7 \%$ through volatilisation. At equilibrium, each year $0.66{ }^{36} \mathrm{Cl} \mathrm{Bq} \mathrm{ha}{ }^{-1}$ leaves the system through volatilisation, $9.16{ }^{36} \mathrm{Cl}$ $\mathrm{Bq} \mathrm{ha}^{-1}$ through drainage of the inorganic pool of the soil and $0.16{ }^{36} \mathrm{Cl} \mathrm{Bq}$ $\mathrm{ha}^{-1}$ through drainage of the organic pool of the soil. At equilibrium, the residence time of chlorine in the system is around 51 years.

In Figure 3 (bottom), the content and the percentage of chlorine in the different system compartments are represented for an underground contamination of ${ }^{36} \mathrm{Cl}$ at the same rate of $10 \mathrm{~Bq} \mathrm{ha}^{-1} \mathrm{yr}^{-1}$. Compared to the atmospheric contamination shown in Fig. 3 (top), the equilibrium of the whole system is reached in a quite similar periodrate. However, the time for the tree compartments $\left(C_{5}\right.$ and $\left.C_{6}\right)$ and for the inorganic pool of the soil to reach their equilibrium is slightly faster, i.e. 50 years instead of 75 years. At equilibrium, there is around $303 \mathrm{~Bq} \mathrm{ha}{ }^{-1}{ }^{36} \mathrm{Cl}$ in the system. This represents $59 \%$ of the chlorine content in the system under the atmospheric deposition 
scenario. During the first 600 years of the model simulation, the chlorine content is highest in the inorganic pool of the soil. After that, most of the chlorine can be found in the organic pool of the soil. However in this scenario this pool only represents $56 \%$ of the total chlorine content, instead of $72 \%$ under the atmospheric deposition scenario. This is compensated by a larger amount of chlorine in the inorganic pool of the soil, i.e. $39 \%$ of the total chlorine content instead of $22 \%$ in previous case.

Compared to an atmospheric contamination, the maximum fraction of ${ }^{36} \mathrm{Cl}$ in the roots $\left(C_{5}\right)$ and tree compartments $\left(C_{6}\right)$ is postponed from year 1 to year 30. A similar retardation effect (from 1 to 20 years) is observed for inorganic chlorine in the forest floor $\left(C_{3}\right)$ but in the soil $\left(C_{1}\right)$ the time to reach a maximum contamination is reduced from 10 to 1 year. Finally, the time to reach a maximum fraction of organic ${ }^{36} \mathrm{Cl}$ in the forest floor $\left(C_{4}\right)$ is increased from 40 to 70 years.

From the $25.2 \times 10^{3} \mathrm{~Bq} \mathrm{ha}^{-1}$ of ${ }^{36} \mathrm{Cl}$ that have entered the system through underground contamination over the 2000 years of simulation, $1.5 \%$ is still in the system. Around $19700 \mathrm{~Bq} \mathrm{ha}{ }^{-1}$ has left the system, 97.3\% through drainage and only $2.7 \%$ through volatilisation. At equilibrium, each year $0.27{ }^{36} \mathrm{Cl} \mathrm{Bq} \mathrm{ha}{ }^{-1}$ leaves the system through volatilisation, $9.66{ }^{36} \mathrm{Cl} \mathrm{Bq}$ $\mathrm{ha}^{-1}$ through drainage of the inorganic pool of the soil and $0.07{ }^{36} \mathrm{Cl} \mathrm{Bq}$ $\mathrm{ha}^{-1}$ through drainage of the organic pool of the soil. This means that compared to the atmospheric contamination scenario, proportionally slightly more chlorine leaves the system through drainage than through volatilisation. In addition, proportionally more chlorine is leached from the inorganic pool of the soil than from the organic pool. The residence time of chlorine in the system is shorter and is around 30 years.

\subsubsection{Chronic versus time-limited}

In Figure 4 (a), the content and the percentage of chlorine in the different compartments are represented for an atmospheric contamination of 10 $\mathrm{Bq} \mathrm{ha}^{-1} \mathrm{yr}^{-1}$ lasting until the equilibrium state has been reached, i.e. 2000 years. From then onwards, the total chlorine content in the system quickly decreases and is reduced by half in 220 years. The leaf surface, the inorganic chlorine pool of the forest floor, the root and the tree compartments are the first pools to be depleted of chlorine. The inorganic pools of the soil and 
the forest floor at first decrease sharply, with 10 year and 1 year half-lives respectively. This decrease however becomes less important after a few years due to a gradual transfer of chlorine from the organic to the inorganic pool. The half-life of the chlorine content in the root and the tree compartments is around 6 years. The organic chlorine pools of the forest floor and the mineral soil require respectively around 15 and 380 years to be reduced by half.

In Figure 4 (b), the content and the percentage of chlorine in the different compartments are represented for a time-limited atmospheric contamination of $10 \mathrm{~Bq} \mathrm{ha}^{-1} \mathrm{yr}^{-1}$ lasting for 100 years. At the point of time when contamination ceases, the total chlorine content in the system is $192 \mathrm{~Bq} \mathrm{ha}^{-1}$. This represents $19 \%$ of the cumulative amount of ${ }^{36} \mathrm{Cl}$ that has entered the system during the contamination period and corresponds to $37 \%$ of the total chlorine content of previous scenario at equilibrium. Once the contamination ceases, the total content is reduced by half in 19 years. The half-lives of the chlorine content in the different compartments are however similar to the equilibrium scenario. As mentioned in previous section, after 100 years, the chlorine content in the organic pool of the mineral soil has not yet reached its equilibrium state. This pool only contains $15 \%$ of its content at equilibrium and by consequence most of the chlorine in the system is in its more mobile form. This explains the much faster depletion of chlorine compared to a system at equilibrium. Finally it has to be mentioned that once the contamination ceases, the chlorine continues to accumulate in the organic pool of the soil for 32 years, from $55 \mathrm{~Bq} \mathrm{ha}^{-1}$ to $63 \mathrm{~Bq} \mathrm{ha}^{-1}$. Most of this organic chlorine is drained from the forest floor into the mineral soil.

In Figure 4 (c), the content and the percentage of chlorine in the different compartments are represented for a time-limited atmospheric contamination of $10 \mathrm{~Bq} \mathrm{ha}^{-1} \mathrm{yr}^{-1}$ lasting for 1 year. At the point of time the contamination ceases, the total chlorine content in the system is $9.8 \mathrm{~Bq} \mathrm{ha}^{-1}$. This represents $98 \%$ of the cumulative amount of ${ }^{36} \mathrm{Cl}$ that has entered the system during the contamination period and corresponds to $1.9 \%$ of the total chlorine content at equilibrium for a continuous contamination. Once the contamination ceases, the total content is reduced by half in around 11 years. The half-lives of the chlorine content in the different compartments are similar to previous scenarios, except for tree and root compartments where the half-life is shorter; 2.5 years instead of 5 years in previous scenarios. This can be explained by the fact that the contamination duration under this scenario is 
very short and that the chlorination process seems not sufficiently significant to catch the chlorine circulating within the system. As mentioned in previous section, after 1 year of simulation only the chlorine content on the external leaf surface has reached its equilibrium state and most of the chlorine in the soil is in its inorganic form. The chlorine is very quickly leached out the inorganic chlorine pool of the soil. By consequence less chlorine is fixed in the organic pools. This explains the shorter half-time for the whole system, tree and root compartments in particular. Finally it has to be mentioned that once the contamination ceases, the chlorine continues to accumulate in the organic pool of the forest floor and the soil for respectively 3.5 years and 60 years, in the inorganic chlorine pool of the mineral soil for 3.5 years.

\section{Conclusion}

In this study, the development and the parameterisation of a model describing the fate of chlorine in a coniferous stand have been described. The model has been evaluated for stable chlorine by performing a range of sensitivity analyses and by comparing the simulated to a limited set of observed values, followed by simulation of a set of ${ }^{36} \mathrm{Cl}$ contamination scenarios. The scenarios differ from each other by external supply, exposure time and source.

From this study it can be concluded that the model is significantly sensitive to variations in the transfer rate values and that the system is more than the sum of all of its components. This highlights the relevancy of this model with its different compartments. In addition, the variability of the simulated chlorine content due to the uncertainty on the transfer rates is bounded within an acceptable range and tends to stabilise at the equilibrium state. The model also estimates realistic values for the chlorine content within the different compartments of the pine forest. The simulated chlorine content in the system reaches its equilibrium after 2000 years, which is in agreement with the timeframe required for the soil carbon pool to reach equilibrium after disturbance.

The sensitivity study has shown that the chlorine content on the leaf surfaces, and to less extent the inorganic chlorine pool of the mineral soil, are nearly unaffected by transfer rate uncertainty. The soil organic chlorine content is, on the other hand, strongly affected by the uncertainty. In general, 
the transfers strongly affecting this compartments content strongly affect the total chlorine content in the system, and consequently the residence time of chlorine in the system; i.e. the leaching of inorganic chlorine from the forest floor and the mineral soil, the uptake by the roots of inorganic chlorine from the soil, the chlorination process in the forest floor and the degradation of organic to inorganic chlorine in the mineral soil.

Based on the sensitivity and the correlation studies, an increase of the chlorination rate in the forest floor would lead to a significant increase of the total chlorine content and its residence time in the system by reducing the amount of soluble chlorine in this layer, and increasing significantly the amount of chlorine immobilised in the organic pools of forest floor and mineral soil. Similarly, a larger uptake of inorganic chlorine by the roots, in particular in case of underground supply, results in a significant increase of the residence time of chlorine in the system, through an enhanced recycling of chlorine between vegetation and soil. On the other hand, an increase of the fluxes through which chlorine leaves the system, results in a decrease of the chlorine content in each compartment and by consequence of its residence time in the system.

Given the large uncertainty of the value assigned to degradation of chlorinated organic compounds in the mineral soil and the fact that the model is very sensitive to this parameter, it is suggested that further studies be performed involving detailed measurements of this parameter in order to obtain a proper estimation of the chlorine accumulation in a forest ecosystem. This is also valid for the leaching of inorganic chlorine from the forest floor and the mineral soil, which are both strongly affected by the climatic conditions at the stand. Under those conditions, since the safety of the radioactive waste disposal needs to be assessed over a very long term, the effect of climate change on ecological conditions (vegetation type, organic matter turnover, water regime) cannot be neglected for an appropriate understanding and modelling of chlorine cycling. Additional measurements would also allow a thorough model validation.

Finally a range of contamination scenarios have been studied to estimate the possible accumulation of ${ }^{36} \mathrm{Cl}$ within the different compartments of a pine stand. For a similar contamination rate, the residence time of chlorine in the system at equilibrium is around 30 years for underground contamination, 
compared to 51 years for an atmospheric contamination. Under both scenarios most of the chlorine leaves the system through drainage. However in the case of an underground source, about two times less chlorine accumulates in the system and proportionally more chlorine leaves the system through drainage than through volatilisation. In addition, proportionally more chlorine is leached from the inorganic pool of the soil than from the organic pool. This can be explained by the fact that under this scenario only $56 \%$ of the chlorine in the soil can be found in its organic form compared to $72 \%$ under an atmospheric contamination scenario. Under the latter, the source directly contaminates the forest floor, where significant portion of the inorganic chlorine may be converted into its less mobile organic form.

Once the atmospheric contamination stops, the tree compartments, i.e. leaf surface, leaves, wood and roots, requires less than 6 years to be depleted by half of their chlorine. The total system however requires around 220 years for a system at equilibrium. Since the organic chlorine pool of the soil, which influences the most the residence time of the chlorine in the sevencompartments system, requires 2000 years to reach its equilibrium state and its maximum content, the time required for the whole system to be depleted by half of its chlorine content is strongly reduced in case of a shorter contamination period.

A comparison of $\mathrm{Cl}$ biodynamics with other terrestrial ecosystems like agricultural lands would be opportune. Compared to crop lands, forest ecosystems are expected to have a higher capacity for internal recycling of chlorine due to its perennial character, deep roots and large amount of organic matter in top soil layer. Most of the compartment and fluxes depicted in this forest model are valid for crop lands too; however some adaptations to the concept of the model (selection, definition and number of compartments, and transfers between compartments) as well as detailed measurements would be required. For instance, the range over which the rate of $\mathrm{Cl}$ transformation in soil varies with ecosystem types, is of high interest. Those processes are influenced by various environmental factors that are not clearly understood due to the lack of studies at the ecosystem scale (Clarke et al., 2009; Redon et al., 2011). 


\section{Acknowledgments}

That study was carried out in the frame of the cooperation contract 048824STR between Andra and SCK.CEN. The MATLAB code has been developed in collaboration with Prof. E. Hanert from UCL/ELI/ELIe. We are grateful to Dr. S. Altmann (Andra) for his help in manuscript improvement.

\section{References}

Ashworth, D., Shaw, G., 2006. A comparison of the soil migration and plant uptake of radioactive chlorine and iodine from contaminated groundwater. J. Environ. Radioact. 89, 61-80.

Bastviken, D., Svensson, T., Karlsson, S., Sanden, P., Öberg, G., 2009. Temperature sensitivity indicates that chlorination of organic matter in forest soil is primarily biotic. Environmental Science and Technology 43, 35693573 .

Clarke, N., Fuksová, K., Gryndler, M., Lachmanová, Z., Liste, H.-H., Rohlenová, J., Schroll, R., Schröder, P., Matucha, M., 2009. The formation and fate of chlorinated organic substances in temperate and boreal forest soils. Environ Sci. Pollut. Res. 16, 127-143.

Colle, C., Mauger, S., Massiani, C., Kashparov, V., Grasset, G., 2002. Behaviour of chlorine 36 in cultivated terrestrial ecosystems. Proceedings of the International Congress ECORAD 2001, Aix-en-Provence (France), 3-7 September 2001. Special issue, Radioprotection 37 Cl, 491-496.

Garten, C., 1978. A compartment model of plutonium dynamics in a deciduous forest ecosystem. Health Physics 34, 611-619.

Garten, C., 1987. Technecium-99 cycling in deciduous forests: review and ecosystem model development. Environment International 13, 311-321.

Goor, F., Thiry, Y., 2004. Processes, dynamics and modelling of radiocaesium cycling in a chronosequence of Chernobyl-contaminated Scots pine (Pinus sylvestris L.) plantations. The Science of The Total Environment 325, 163180.

Hillel, D., 1998. Environmental Soil Physics. Academic Press. 
Holmberg, M., Hari, P., Nissinen, A., 1989. Model of Ion Dynamics and Acidicfication of Soil: Application to Historical Chemistry Data of Sweden. In: J. Kamari and D.F. Brakke and A . Jenkins and S.A. Norton and R.F. Wright (Ed.), Regional Acidification Models. Springer-Verlag, Berlin Heidelberg, pp. 229-241.

Hurtevent, P., Thiry, Y., Levchuk, S., Yoschenko, V., Madoz-Escande, C., Henner, P., Leclerc, E., Kashparov, V., Submitted. Translocation of ${ }^{125}$ I, ${ }^{75} \mathrm{Se}$ and ${ }^{36} \mathrm{Cl}$ to edible parts of radishes, potatoes, wheat and beans following foliar contamination: a field experimental approach. Proceeding submitted for ICRER 2011, 19-24 june 2011, hamilton, canada.

Kashparov, V., Colle, C., Levchuk, S., Yoschenko, V., Zvarich, S., 2007. Radiochlorine concentration ratios for agricultural plants in various soil conditions. J. Environ. Radioact. 95, 10-22.

Liberloo, M., Luyssaert, S., Bellassen, V., Djomo, S. N., Lukac, M., et al., 2010. Bio-energy retains its mitigation potential under elevated $\mathrm{CO}_{2}$. PLoS ONE 5.

Lovett, G., Likens, G., Buso, D., Driscoll, C., S.W.Bailey, 2005. The biogeochemistry of chlorine at Hubbard Brook, New Hampshire, USA. Biogeochemistry $72,191-232$.

Mualem, M., 1976. A catalogue of the hydraulic properties of unsaturated soils. Research project no. 442, Technion, Israel Institute of Technology, Haifa, Israel.

Öberg, G., Holm, M., Sanden, S., Svensson, T., Parikka, M., 2005. The role of organic-matter-bound chlorine in the chlorine cycle: a case study of the Stubbetorp. Biogeochemistry 75, 241-269.

Redon, P.-O., Abdelouas, A., Bastviken, D., Cecchini, S., Nicolas, E., Y., Thiry, 2011. Chloride and organic chlorine in forest soils: Storage, residence times, and influence of ecological conditions. Environmental Science and Technology 45, 7202-7208.

Thiry, Y., 2010. Contribution à l'étude du cycle biogéochimique du chlore en écosystmème forestier : cas d'un peuplement de pin sylvestre (exploitation des donnés du rapport SCKCEN-R-4922). Rapport Andra 
ENV.NT.ASTR.10.0068, Agence Nationale pour la gestion des Déchets Radioactifs, France.

Van Hees, M., Vandenhove, H., 2009. Chlorine levels in compartments of a pine forest in mol, belgium. Restricted contract report SCK-CEN-R-4922, Belgian Nuclear research centre.

Vincke, C., Thiry, Y., 2008. Water table is a relevant source for water uptake by a scots pine (Pinus sylvestris L.) stand : evidences from continuous evapotranspiration and water table monitoring. Agricultural and Forest Meteorology 148, 1419-1432.

Vogt, K., Vogt, D., Palmiotto, P., Boon, P., OHara, J., Asbjornsen, H., 1996. Review of root dynamics in forest ecosystems grouped by climate, climatic forest type and species. Plant and Soil 187, 159-219.

White, P., Broadley, M., 2001. Chloride in soils and its uptake and movement within the plant: a review. Annals of Botany 88, 967-988.

Winterton, N., 2000. Chlorine: the only green element-towards a wider acceptance of its role in natural cycles. Green Chemistry 2, 173-225.

Wosten, J. H. M., Lilly, A., Nemes, A., Le Bas, C., 1999. Development and use of a database of hydraulic properties of European soils. Geoderma 90, 169-185.

Wutzler, T., Reichstein, M., 2006. Soils apart from equilibrium consequences for soil carbon balance modelling. Biogeosciences Discuss. 3, 1679-1714. 


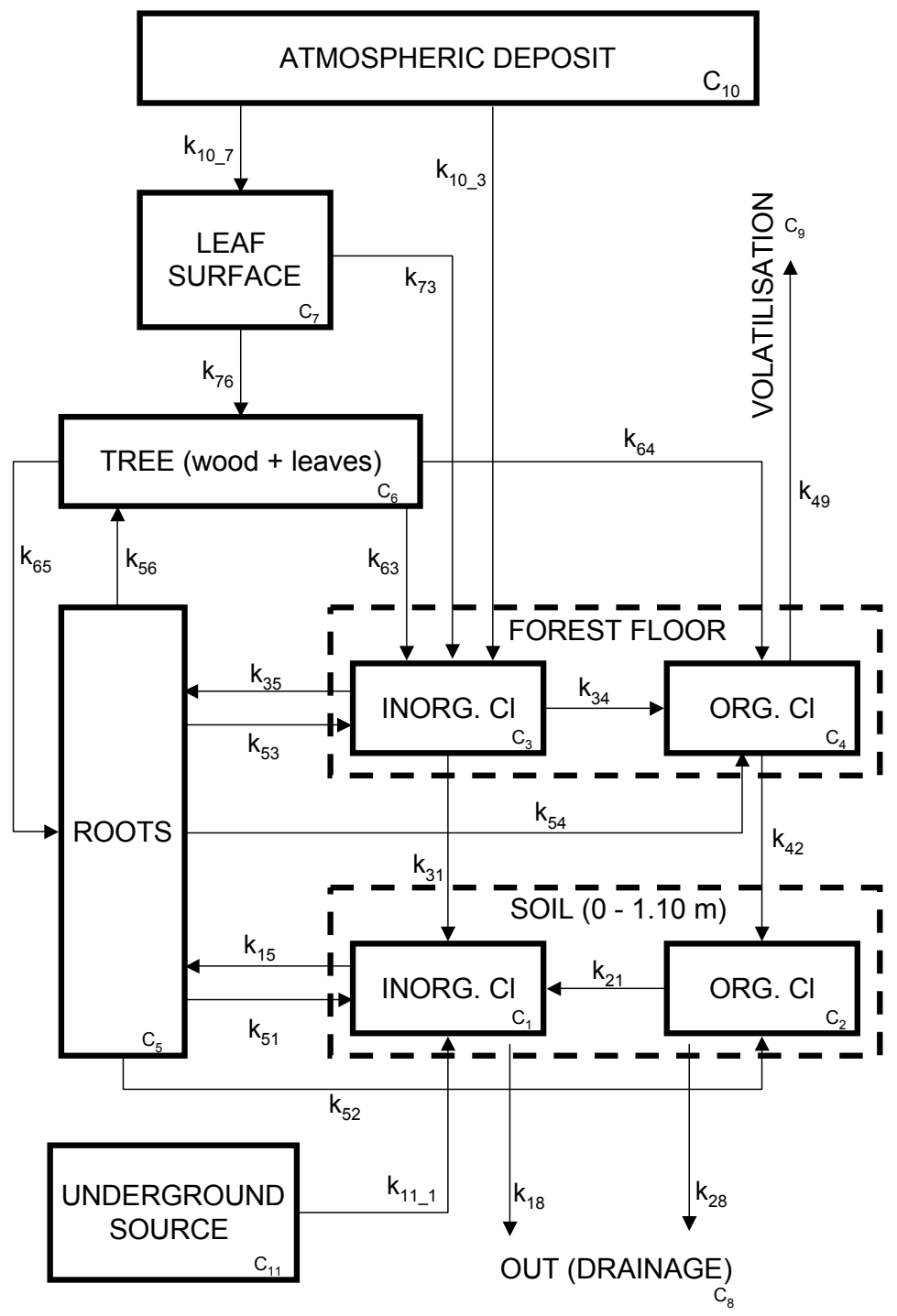

Figure 1: Model of chlorine cycling in a coniferous forest ecosystem with rates of transfer $k_{i j}$ between compartments $C_{i}$ and $C_{j}$. 


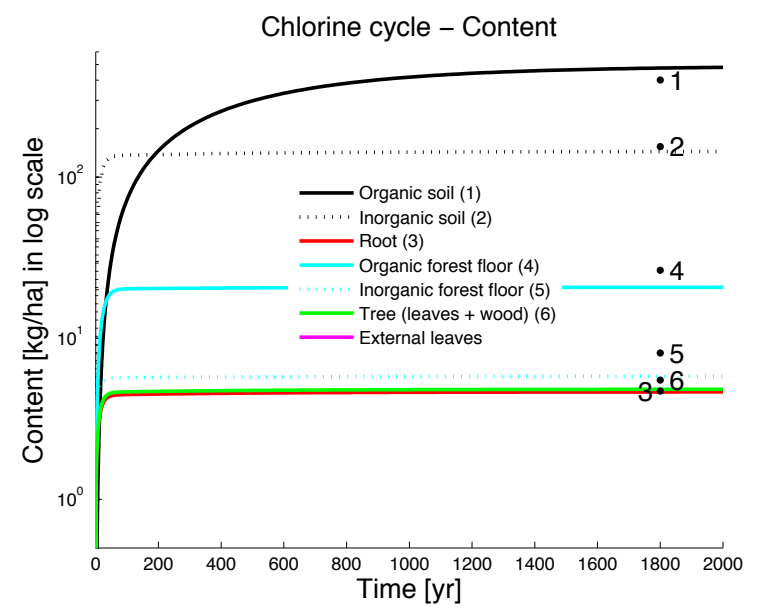

Figure 2: Evolution over a period of 2000 years of the chlorine content (log scale) within the different compartments given a chronic atmospheric deposition of 12.6 $k g C l h a^{-1} y^{-1}$. 

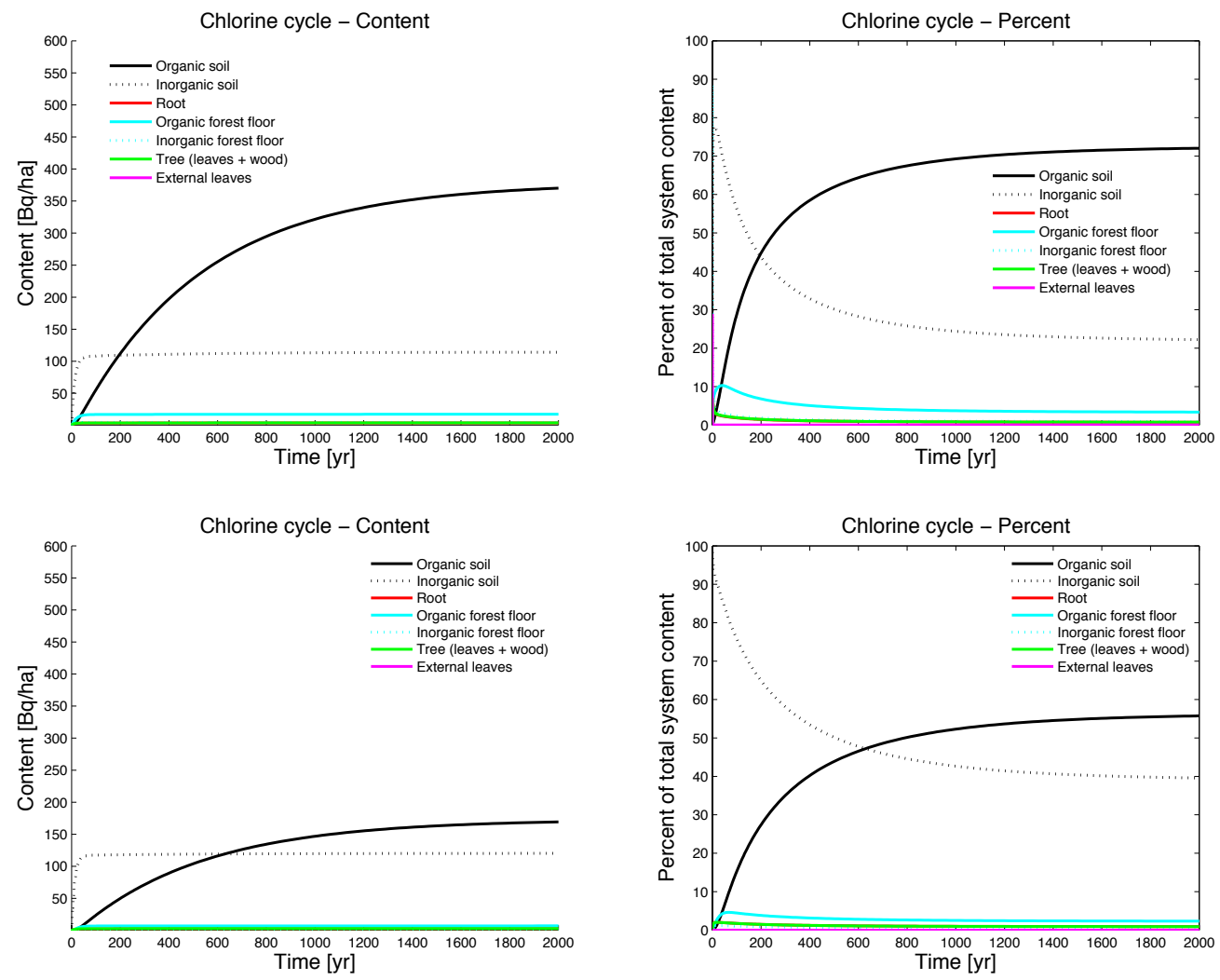

Figure 3: Evolution over a period of 2000 years of the chlorine content and the partitioning within the compartments of the system given a chronic atmospheric

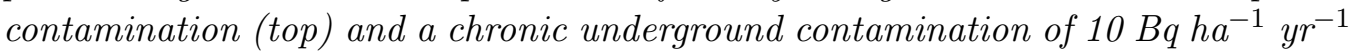
of ${ }^{36} \mathrm{Cl}$ (bottom). 
(a)
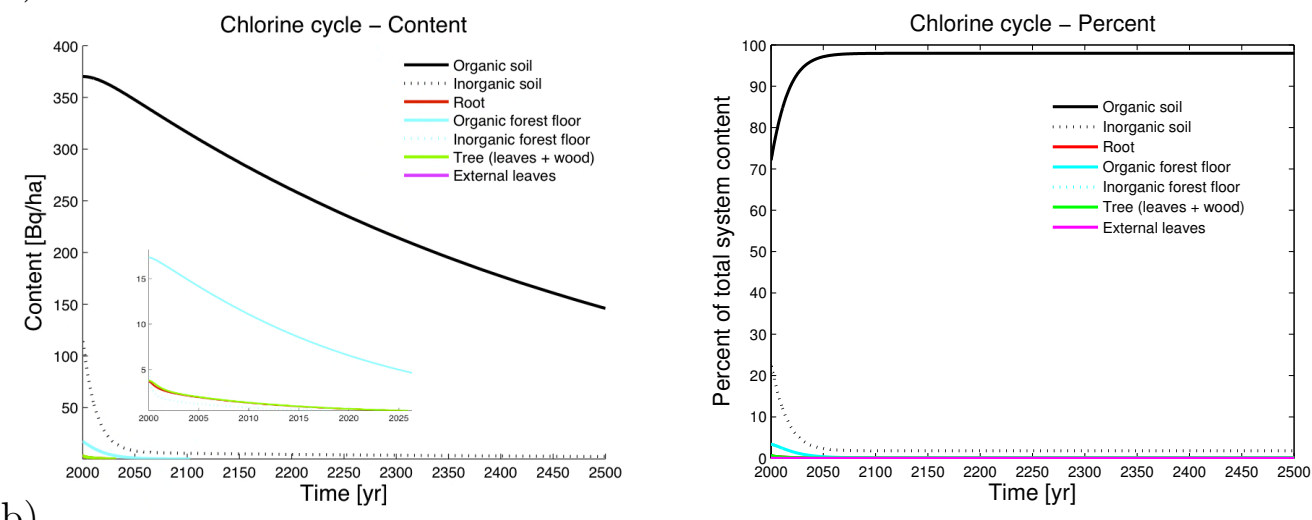

(b)
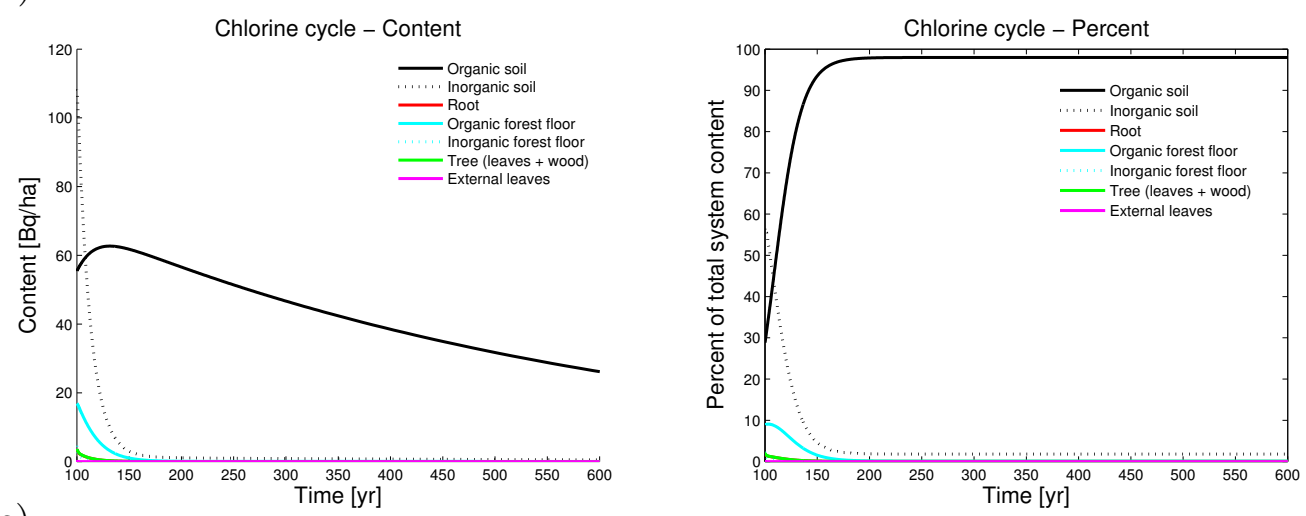

(c)
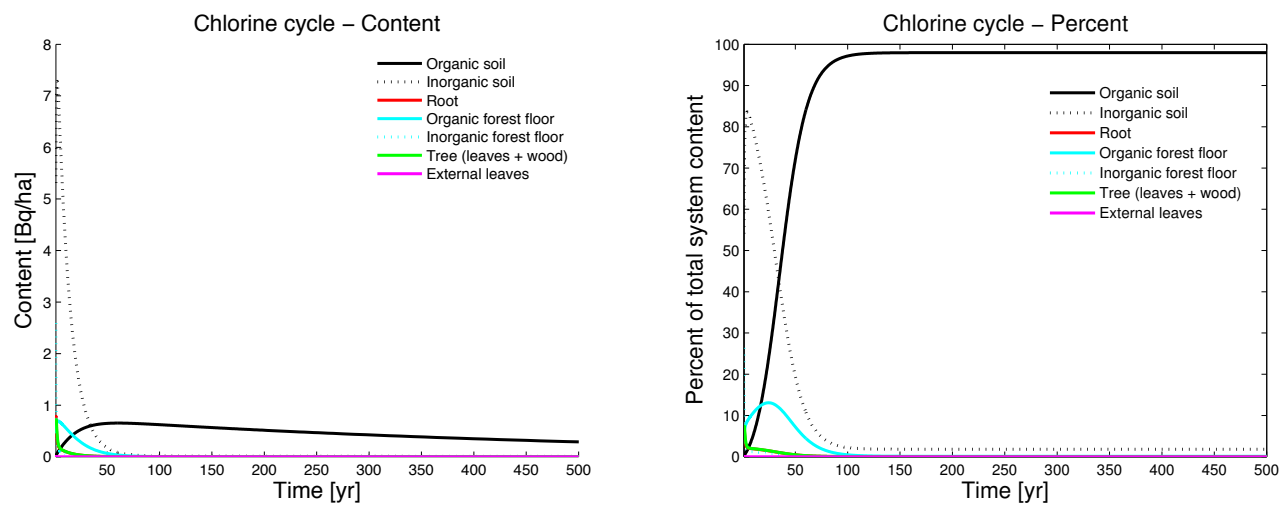

Figure 4: Evolution over a period of 500 years of the chlorine content and partitioning within the compartments once a time-limited atmospheric contamination

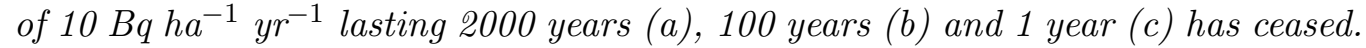

